\title{
Flipped Learning for Repurposing EFL Class Time in Moroccan University
}

\author{
Mohamed Jaafari, PhD
}

Cadi Ayyad University, Morocco

Doi: 10.19044/ejes.v6no4a1

URL:http://dx.doi.org/10.19044/ejes.v6no4a1

\begin{abstract}
This article demonstrates the way flipped learning is implemented in response to new learning environment to solve inadequacies in setting and enhance learning and teaching practices. Accordingly, in the Faculty of Arabic Language in Marrakech, flipped classroom is adopted as a pedagogical solution to approach novel occurrences in teaching and learning context, namely students' irregular classroom attendance and quantity and variety of instructional material the students have to assimilate within an allotted time to meet deadlines. The question raised seeks to discover the extent flipped pedagogy is successful in improving the teaching and learning performances despite the mentioned inadequacies. For this purpose, and following flipped methodology, the course is disseminated to the learners through a technologybased tool of communication and physical classroom time is managed for discussion purposes rather than lecturing in a traditional way. The success of this implementation is measured through the assessment of the students' performance in both online quizzes and on-campus exams. Pedagogical benefits and pending points in the implementation of such method in this particular context is thoroughly debated with the purpose to highlight the implications of this empirical case study for educators and researchers.
\end{abstract}

Keywords: Flipped classroom, digital tools, pedagogy, EFL.

\section{Introduction}

Recent years have witnessed a rapid trend away from traditional methods of teaching, learning and disseminating learning knowledge. Accordingly, one of the prodigious novelties in the realm of modern approaches in education and pedagogy is the incorporation of educational technologies which provide essential support in facilitating teaching and learning. This reform is brought to life in response to the demands of urgent needs in specific educational contexts and social change. Flipped classroom approach is one of the pedagogical devices created not only to facilitate but 
also to ameliorate learning and teaching and address contextual hindrances or inconsistencies such as crowded classes, irregular attendance of learners and financial constraints which have pressures on educational institutions.

The present paper is concerned with an exploratory experiment in implementing flipped learning at the faculty of Arabic Language, Marrakech in Morocco. The context of research relates to the reforms have been lead to introduce novel courses and academic studies such as Modern Language Studies. The majority of the students enrolled in the faculty of Arabic language come from Moroccan High schools specialized in Islamic studies with almost no experience with foreign languages.

Several elements have a bearing on my motivation to undertake the experiment. The motives stem from the field of work itself. First, the background of the students enrolled in the newly introduced course is varied. The students involved in this experience attend my classes of grammar and they are 60 in their group. They are of different ages, parents and bachelors, including high school graduates, working and even retired people. The working people come from different vocational sectors, namely nurses, clerks and school teachers. On-campus attendance is not compulsory. Hence, considerable constraints have risen to the surface. The first constraint is the need to create systematic English language classroom conducts for low foreign language proficiency students to help them enter the realm of English language learning. An additional reason behind this project is the constraint of the irregular attendance of the students who are busy with their jobs elsewhere. Therefore, these inconsistencies coupled with class-time insufficiency to cover the course modules appropriately and at ease have made the search for fitting instructional alternative an urgent need.

Given the account above, this experimental endeavour aims to map out the impact of the implementation of flipped pedagogy on the students' academic performance in and outside class.

Two main questions guide the present research. They are as follows:

1. How can flipped learning pedagogy help exploit effectively home and class time to enhance learning?

2. What technologies to be integrated to engage students in flipped learning?

To answer these investigative questions, a methodical strategy is implemented, following the fundamental principles of flipped learning. For organizational reasons, this paper is divided into sections; the first section highlights the conceptual background underlying the present experience. The next section demonstrates the methods applied followed by a section which encompasses the results and the discussion of the results. 


\section{Theoretical Framework}

Flipped learning is also referred to as flipped pedagogy, flipped classroom, backward classroom, inverted classroom, reverse teaching. The term was first seen as a simple reverse of the activities traditionally designed for class work with those traditionally designed for home work. It all started with two American high school science teachers, Jonathan Bergmann and Aaron Sams, who first thought of flipping their classroom in 2007 (Bergmann \& Sams, 2009). Their students missed lessons in classroom, but the teachers decided to make them not miss learning by recording the PowerPoint lessons on videos and share these videos with their students (Bergmann \& Sams, 2009). Though Bergmann and Sams accredited many people before them who inspired their method, the flipped strategy proliferated and spread all over the world starting with their experience. Flipped strategies and techniques benefit from the growing accessibility, affordability and global omnipresence of technology to make education changing every instant. As a result, flipped pedagogy has become a tradition with its own norms, principles and procedures (Bergmann \& Sams, 2012).

Varied definitions have been proposed to explain the concept of flipped learning. In this experiment, flipped learning is implemented with the following meaning (Flipped Learning Network, 2014):

Students gain first exposure to new material outside of class, usually via reading or lecture videos, and then use class time to do the harder work of assimilating that knowledge, perhaps through problem-solving, discussion, or debates.

On this basis, flipped learning strategy departs away from the traditional mode of instruction in many aspects. Traditionally speaking, the teacher as a lecturer is a sage acting on stage in front of a group of students who passively struggle to grasp and consume what is lectured to them, record it to remember and apply individually the learning to new situations as forms of exercises at home. The focus in the traditional methodology is centered on the lecture as content and the lecturer as source of the content and knowledge. In contrast, with flipped methodology, the teacher moves aside and becomes a guide, a facilitator who supports and accompanies the learners in the construction of their own knowledge for themselves. Hence, the learners are actively involved in the learning operation to create knowledge.

Unlike the traditional four-wall closed context of the classroom, the students are exposed individually to the course material for the first time before class time in a relaxed atmosphere of the home and over a sufficiently large span of time. In the flipped pedagogical approach, direct instruction moves from the group learning space to the individual learning space, and the resulting group space is transformed into a dynamic, interactive learning environment where the educator guides students as they apply concepts and 
engage creatively in the subject matter. (Flipped Learning Network, 2014, para. 1).

This step affords low-achievement learners opportunity to acquaint themselves with the learning resources shared or designated by the teacher at their ease and according to their own personal pace of learning. Thus, flipped pedagogy proposes solutions to change the low outcomes of some students traditionally termed as "low-ability" learners. The latter term implies that this group of students has reached their cognitive limit in learning. Therefore, low achievement is traditionally attributed to the limited ability in the mind of the students. On the opposite, flipped pedagogy has changed the traditional mindset, focusing on the learner's performance as an outcome of the learners' effort, strategy, attitude and engagement rather than mind ability. A change brought to these factors may reflect positively on learning outcome. As an example, the teacher reacts to the needs and learning style of individual student by differentiating modes of instruction, namely swapping the sequences of the learning levels or involving mediums of instructions such as audiovisual tools.

The principles studied up to now find strong support in the most famous theories of learning. Hence, the success of flipped pedagogy is explained by three key assumptions about the science of learning proposed by Bransford et al.:

To develop competence in an area of inquiry, students must:

a) have a deep foundation of factual knowledge,

b) understand facts and ideas in the context of a conceptual framework, and

c) organize knowledge in ways that facilitate retrieval and application. (2000, p. 16)

Flipped strategy principles also converge with the fundamentals underlying renowned theories in pedagogy. Accordingly, to reference Flipped Classrooms, Allen (2014) refers to the frameworks of the following theorists: 1. Lev Vygotsky, the Russian developmental psychologist known for the theory of the development of higher cognitive functions, calls for the incorporation of group work in classroom activities. Group work tasks utilize problem solving and knowledge Application strategies to help learners achieve high levels of understanding.

2. Benjamin Bloom, the American educational psychologist reputed for the theory of the mastery learning model. He states that individual learners should be time to work at own pace, and receive regular formative assessments to assimilate essential knowledge before getting ready to learn succeeding material

3. B.F. Skinner, the American Psycho-Behaviourist who proposed theories of reinforcement and radical behaviourism, insists on applying reinforcement and prompting feedback in sequential learning for the learners master learning before moving on to additional learning. 
Above are only some of the theoretical frameworks which are applicable to flipped learning pedagogy. They testify its credibility and theoretically proven practices. The next section of the paper relates to the methodology of flipped strategy. The section describes the methods, techniques, tools and steps of implementation.

\section{Methods of Flipped Strategy}

In traditional sequencing of learning levels, remembering and understanding as lower levels of learning occur in class, while higher levels of learning such as analyzing and creating are usually left as home activities. The figure below contrasts between the two differing strategies (Honeycutt, 2017):

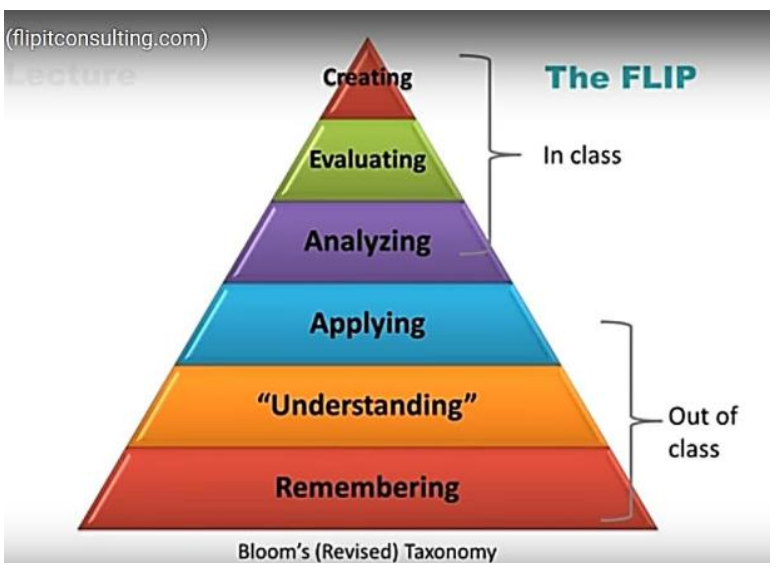

Figure 1: Traditional \& flipped learning sequences

In the flipped classroom model, the learning levels are flipped. The home time is invested in decoding the learning material for cognitive digestion and assimilation. Remembering results from the previous steps in preparation for ensuing steps which are applying and analyzing the assimilated knowledge.

In terms of the classification of levels of mastery of learning, the students perform the lower levels of cognitive work outside class. At this stage, each student individually receives new material disseminated electronically by the teacher. The student's task is to understand, explain, summarize, classify and remember the material. Within this stage as well, the students may have recourse to online discussion groups for clarification. If stuck at a point while reading or viewing the shared lesson, they call teacher to come into play to supplement or modify the content. All of these procedures and practices may take place online asynchronously or synchronously through Whatsapp, webinars or Google Hangouts. The material concerned may take the form of video compilation or PDF, word and PowerPoint files. Hence, the 
home ample time is appropriately exploited for the purpose of self-learning, knowledge-building and engagement.

Once back to class in the presence of the teacher, the students apply and implement their learning in collaborative exercises to demonstrate understanding. Because the chances of interacting with peers and instructor are increased, the students deepen and expand understanding through analysis of the instructional content. With such support now available in class, the students focus on higher forms of cognitive work, namely comparing, contrasting, differentiating, examining and questioning.

The final step in this approach relates to post-class meta-reflection, creation and assessment. At this stage, inquiries resume online and in discussion groups. Students or teacher may produce and share holistic summaries of the previous contents.

Pre-exam online quiz comes in preparation for the final in-class exam. A compulsory online quiz is devised as an opportunity for students' selfevaluation and learning assessment. In-class exam is created following the online quiz model. The results from this latter will demonstrate the extent learning has been taking place and how successful the implementation of flipped learning strategy is.

The following figure designed by Colette (2015) summarizes the integrated steps of flipped learning approach discussed hitherto.

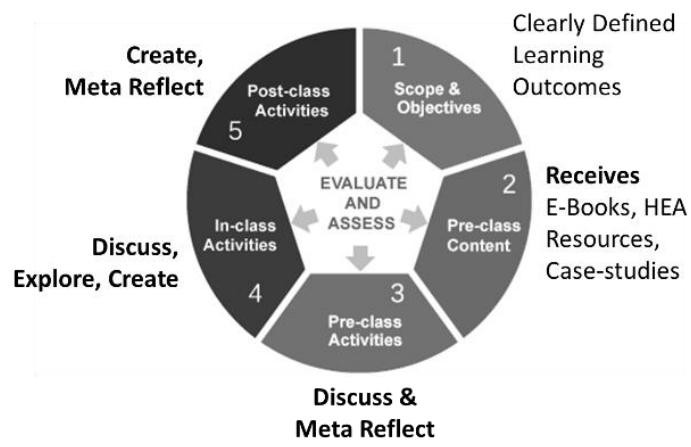

Figure 2: Steps of flipped strategy

In a successful flipped pedagogy, the educator is required to define clearly the objectives to be achieved and take these objectives into consideration at all stages of the implementation. Therefore, flipped classroom should be able to:

- increase teacher-student contact time through discussion and debriefings.

- increase student responsibility through challenging student inquiry in and out of class.

- engage students in knowledge construction. 
- allow low-achievement students to catch up with their peers through selfpaced modality of delivery

- enable students with self-evaluation and critical thinking strategies

1. Pre-assignment Tools (Honeycutt, 2016).

- Video (your own or someone else's) -Podcast

- PowerPoint (or Slide deck) Tutorial -Reading (with worksheet for annotation by student)

- Worksheet with Guided Steps, Q\&A -Writing Assignment

- Collaborative Work Online (BlackBoard, Google Docs or other app)

2. In-class activities

- Group presentations -Group discussion -Brainstorming

- Group or Individual Research - Debates -Scenarios / Case

Studies - Student-Designed Quiz

3. Assessment (Flipped Classroom Resources, 2017).

Assessment is critical to knowing what individual students are learning and adjusting in-class activities accordingly. Assessment shows which student might need individual attention, and which topics might need to be taught differently.

a. Pre-Test: given before starting in-class activities to gauge where students are in their learning. Pre-Test can be:

- Online (Google Form)

- Clickers

- Poll Everywhere

- Paper (short answer)

b. In-Class Activities:

- Activity Worksheets for guided learning

- Questions from students

- Poll Everywhere

- Clickers

- Collaborative work (Google Docs)

c. Post-Test and Follow-Up

- Post-Test at end of class

- Exit Ticket filled out by students

- Online chat follow-up

- Survey student opinion of lesson

The subsequent section of the present article depicts the application of flipped strategy discussed above in a very special context. The section analyses reasons for implementation, procedures, assessment tools and results. 


\section{Application of Flipped Methods}

The implementation of flipped classroom is changing from context to another. The stages are managed differently with various levels of depth. The lesson below exhibits particular management of steps that fits well in the context of the Faculty of Arabic Language and the type of students enrolled in the Modern Language Studies Course. Specifically, the lesson concerns grammar points.

\section{Stage One}

a. Planning the lesson: Grammar points

Definition + rules + Use + examples and diagrams / figures + Practice exercises

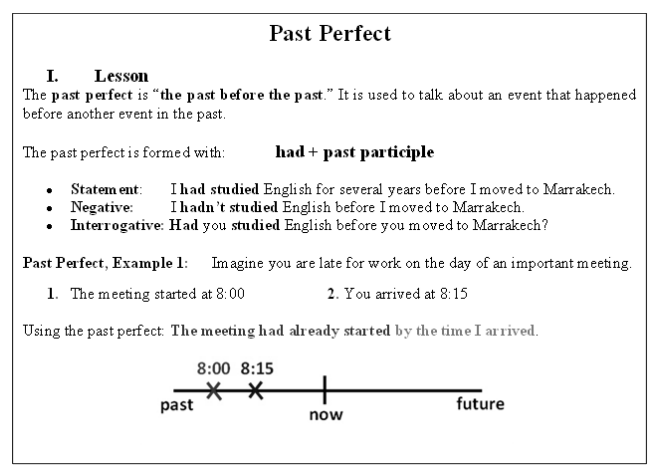

Figure 3: Part of the content to be shared

b. Collaboration: A colleague reviews the lesson

c. Conversion of the lesson into PDF format

d. Sharing with students (online medium): WhatsApp study group.

2. Self-regulation: Students take advantage of technological and pedagogical practices of distance education (self-learning)

3. Social-regulation: Social learning through synchronous and asynchronous exchanges between peers or the teacher.

4. Variation and support:

a. Online practice with foreign teachers on videos ("Engvid.com") in addition to interactive exercises (englisch-hilfen.de/en). 


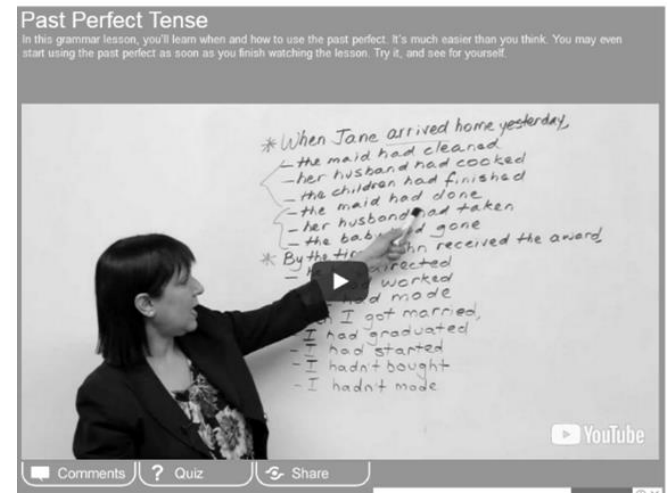

Figure 4: lesson from Engvid.com

b. Online quiz: Students react to quiz on Google Form.

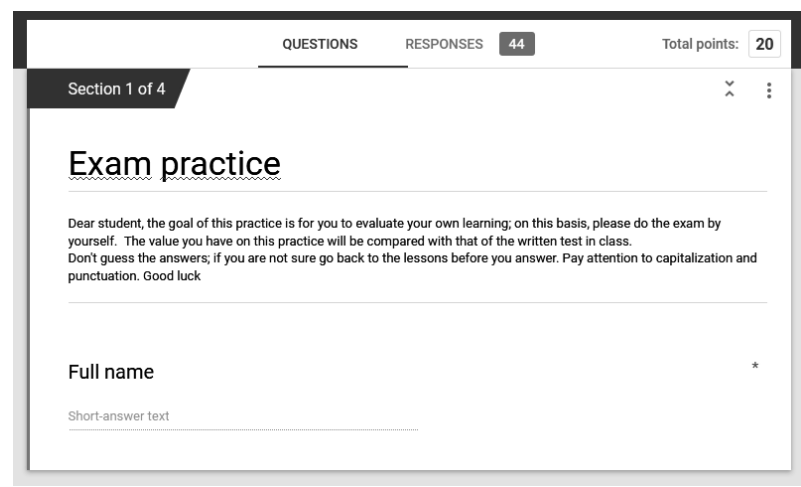

Figure 5: Grammar quiz on Google Form

The prelude to the quiz highlights the objectives of the quiz and orients the students toward self-assessment. It goes as follows:

Dear student, the goal of this practice is for you to evaluate your own learning; on this basis, please do the exam by yourself. The value you have on this practice will be compared with that of the written test in class. Don't guess the answers; if you are not sure go back to the lessons before you answer. Pay attention to capitalization and punctuation. Good luck

The quiz is parted into 3 sections with 3 different formats of exercises. The first type is a multiple choice task. 


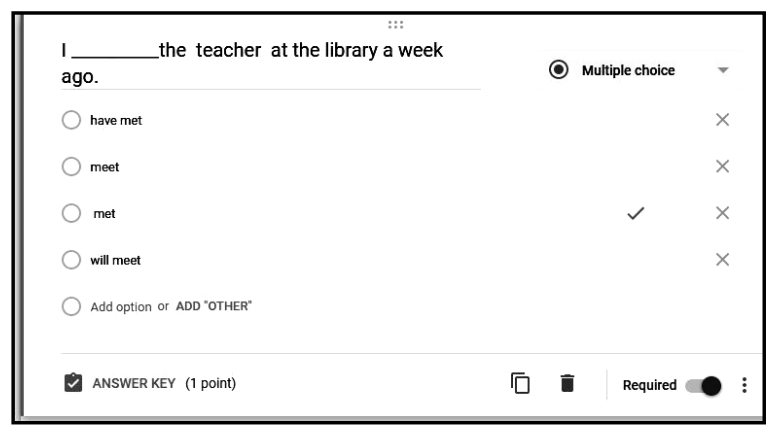

Figure 6: Example of Multiple Choice exercise

The second type is sentence transformation.

\begin{tabular}{l}
\hline Section 3 of 4 Rewrite the sentences as indicated \\
Description (optional) \\
"I am here". He told her ................ * \\
Short-answertert \\
The president elected the players. The players .......... \\
short-answer tert
\end{tabular}

Figure 7: Example of sentence transformation exercise

The third format is supplying the correct tense of the given verb.

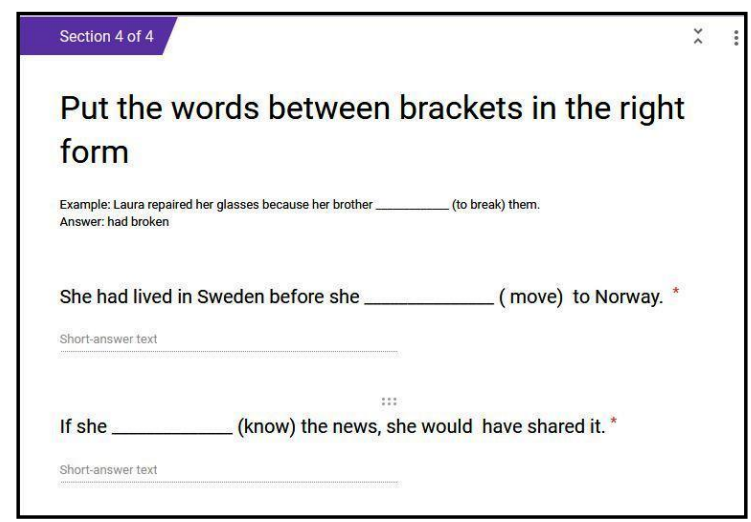

Figure 8: Example of verb tense exercise 
c. Class Meeting: The students and teacher discussion of difficult points Metadebate.

Students and teacher review the most difficult parts of the course; in the present case study, the students found difficulties with present perfect and past perfect, so the debate focused solely on these tenses. At the same time, the students and teacher evaluate the resources delivered by the teacher and the students' performance. Then, they together evaluate the googleForm quiz, namely the quiz items and the students' performance on it. Finally, agreement is set up on paper exam schedule.

\section{Results and Discussion}

The figure below summarizes the results from the Google Quiz the students undertook after having familiarized themselves with the content.

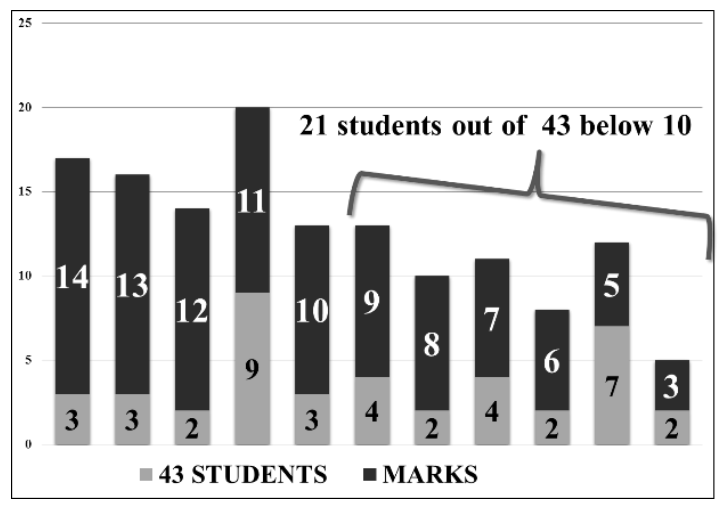

Figure 9: Students' performance on GoogleQuiz

Only 43 students out of 60 answered the quiz. 17 students didn't do the quiz for fear of not being able to succeed on it. 22 students out of 43 have got above 10 over 20 . After class discussion and implementation of learning in exercises, the students took a paper exam in class and the results are as follows:

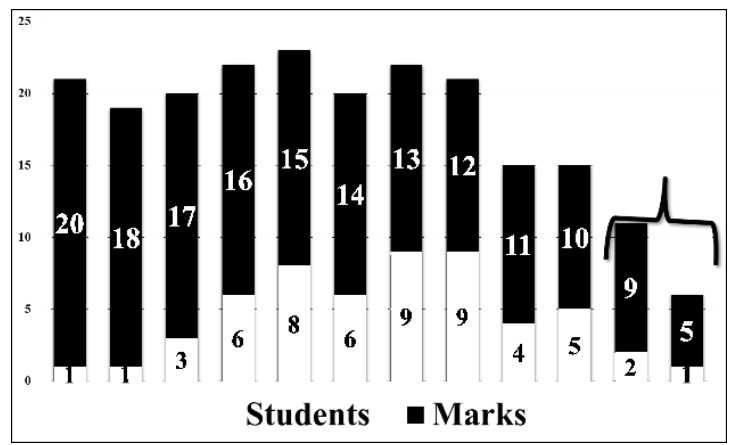

Figure 10: Students' performance on paper exam 
All students were present except for 5 who were absent for personal reasons. All students performed well except for 3 . The astonishing is that many students were brilliant and had best marks. The present results attest to the positive impact of the implementation of flipped strategy on the students' learning. The differences between the results extracted from the online quiz before class discussion and the results extracted from the paper exam after class debate are traced back to the benefit the students have drawn from the class discussion; that is, class time is best beneficial to the students whenever exploited for content debate rather than content presentation.

The analysis conducted on the basis of the results from the performance of the students demonstrates that flipped learning pedagogy has driven the students towards high performance. The reason behind this assumption is that class time and home time are exploited effectively to the betterment of the students learning. Hence, flipped learning strategy not only facilitates learning and teaching but also maximizes the opportunities of quality learning for different students preferring different learning styles.

Equally important is the development of the underachievers. They benefit from the possibility of viewing and reviewing the content at home to maximize their engagement and the degree of input. They also benefit from the quiz online done at their ease. Therefore, the destructive emotional and motivational dynamics such as anxiety and alienation interfering with the students' processing of learning are annihilated. Krashen (1981, p. 23) claims that "The students who feels at ease in the classroom .... may seek out more intake by volunteering ... and may not be more accepting of the teacher as a source of input." They would acquire in the learning strategies of autonomous learners. Prince (2004) adds that learning is more effective when the students are actively involved and assume learning responsibilities. Furthermore, lowachieving students compensate in the debate session for what they have failed to assimilate in the previous steps.

High achieving students in their turn enhance and demonstrate their proficiency level in several occasions, namely online quiz, class debate and final paper exam. In comparison with their performance in a traditional course context, the proficient learners exhibit more engagement as they invest greater effort and spend ampler time with educationally purposeful activities Kuh et al. (2008). An increase in the student's motivation endows students with impetus to regulate their own learning process. Zimmerman reports that "selfregulated learners proactively seek out information when needed and take the necessary steps to master it" (1990, p. 4). This assumption as it is the case with flipped learning pedagogy asserts that self-regulated learning is inductive to educational achievement.

The important gain from implementing flipped pedagogy is the continuous availability of the teacher outside class time and online. In the case 
of the present experiment, two representatives of the students report the inquiries shared on WhatsApp discussion group by the students. Thus, the teacher reacts to these inquiries by supplementing or modifying the content. The teacher, hence, assumes the responsibility of following and assessing the development of the learning and the degree of the students' engagement.

In fact, the role of the instructor is even more demanding in a flipped classroom than in an ordinary lecture-based one. Professional educators have to acquire ample knowledge about the subject taught to provide students with individualized feedback since the teacher-student interaction is increased in class. Professional educators are also required to continuously reflect on class performance and assess practices. Connection among educators and acceptance of constructive criticism from colleagues is a requisite for leadership in flipped learning context. Finally, professional educator allow for manage positively real differentiation among students in a transparent atmosphere reaching for complementarity between students and far from fierce competitiveness. Mazur reflects the way flipped classroom redefines the role of the educator:

So, I think the role of the instructor, rather than becoming the source and the deliverer of knowledge, will become much more that of a facilitator, of a coach. ... Rather than just telling you what I know, I'm going to probe your knowledge and push you to build your own knowledge. (2013, para. 20).

\section{Conclusion}

Flipped learning approach really helps to innovate pedagogy. In fact, the advent of flipped learning marks a dramatic shift of the paradigm of teaching. It brought about a change in the role of the content material, responsibilities of the learner and instructor, and the utility of the spatial and temporal constituents of the learning environment. The results from this experiment have implications of paramount importance to the stakeholders in the educational realm. For the implementation to succeed, educators are required to conduct comprehensive and systematic evaluation of learning needs. The inclusion of technology should be both selective of free and simple tools and methodically oriented. The endeavor of the implementation has to let pedagogy drive technology not vice versa. Finally, Teacher-training programs is meant to spare enough room and space for techniques of basing teaching practices on flipped learning strategies. 


\section{References:}

1. Allen, S. (2014). Shifting the instructional paradigm: Articulating a set of current practices in flipped library instruction. Tennessee Libraries, Vol. 64 No. 3, Retrieved from: http://www.tnla.org/?page=TL64_3_shifting

2. Anderson, L. W., Krathwohl, D. R., \& Bloom, B. S. (Eds.). (2001). A taxonomy for learning, teaching, and assessing: A revision of Bloom's taxonomy of educational objectives. New York, London: Longman.

3. Anderson, L. W., \& Bloom, B. S. (2014). A taxonomy for learning, teaching, and assessing: A revision of Blooms. Harlow: Pearson.

4. Bergmann, J., \& Sams, A. (2009). Remixing chemistry class: Two Colorado teachers make vodcasts of their lectures to free up class time for hands-on activities. Learning \& Leading with Technology, 36(4), 22-27. Retrieved from http://files.eric.ed.gov/fulltext/EJ904290.pdf

5. Bergmann, J., \& Sams, A. (2012). Flip your classroom: Reach every student in every class every day. Eugene, Or.: International Society for Technology in Education.

6. Brame, C. (2013). Flipping the classroom. Vanderbilt University Center for Teaching. Retrieved from http://cft.vanderbilt.edu/guidessub-pages/flipping-the-classroom/.

7. Bransford, J. D. ed., Brown, A. L. ed., \& Cocking, R. R. ed. (2000). How people learn: Brain, mind, experience, and school. Washington: National Academy of sciences.

8. Colette, M. (2015). Flipped learning: Transforming teaching and learning. Retrieved from https://slideplayer.com/slide/9411865/

9. Ezekiel, R. (2012, May 31). Past perfect tense [Video file]. Retrieved from https://youtu.be/9QU5bqq18Kg

10. Flipped Classroom Resources: Assessment. (2018).Retrieved from https://libguides.lehman.edu/c.php?g=457910\&p=3129829

11. Flipped Learning Network (FLN) (2014). The four pillars of F-L-IPTM. Retrieved from https://flippedlearning.org/wpcontent/uploads/2016/07/FLIP_handout_FNL_Web.pdf

12. Honeycutt, B. (2017). What's the FLIP? Retrieved [11/22/2019] from https://www.youtube.com/watch? v=rGlbgc4qYgo

13. Honeycutt, B. (2016). Ready to flip: Three ways to hold students accountable for pre-class work. Retrieved from http://www.facultyfocus.com/articles/blended-flipped-learning/readyto-flip-three-ways-to-hold-students-accountable-for-pre-class-work/

14. Krashen, S.D. (1981). Second language acquisition and second language learning. Prentice-Hall International.

15. Kuh, G. D., Cruce, T. M., Shoup, R., Kinzie, J., \& Gonyea, R. M. (2008). Unmasking the Effects of Student Engagement on First-Year 
College Grades and Persistence. The Journal of Higher Education, 79(5), 540-563. https://doi.org/10.1080/00221546.2008.11772116

16. Mazur, E. (2013, March 13). The flipped classroom will redefine the role of educators. EvoLLLution Blog. Retrieved [11/22/2019] from https://evolllution.com/revenuestreams/distance online learning/audio-flipped-classroom-redefinerole-educators-10-years/

17. Prince, M. (2004). Does Active Learning Work? A Review of the Research. Journal of Engineering Education, 93(3), 223-231. https://doi.org/10.1002/j.2168-9830.2004.tb00809.x

18. Zimmerman, B. J. (1990). Self-regulated learning and academic achievement: An overview. Educational Psychologist, 25(1), 3-17. https://doi.org/10.1207/s15326985ep2501_2Retrieved from https://ciel.viu.ca/sites/default/files/self_regulated_learning_and_acad emic_achievement_an_overview_0.pdf. 